\title{
Lung function of farmers in England and Wales
}

\author{
RF HELLER, DM HAYWARD, MTB FAREBROTHER
}

From St Thomas's Hospital Medical School, London

ABSTRACT A study was performed to compare respiratory symptoms and lung function measurements in a sample of male farmers and farmworkers in different regions of England and Wales with the results obtained in a similar number of control men working in industries in the same areas. A total of 428 farmers and farmworkers drawn from 146 farms were studied. The prevalence of symptoms of chronic bronchitis assessed by the Medical Research Council questionnaire did not differ between farmers and controls. Farmers were older, taller, and heavier than controls; were less likely to smoke; and had significantly higher forced vital capacity (FVC). When each of these factors was taken into account, together with social class and geographical region, in a multiple linear regression analysis farmers were found to have significantly lower forced expiratory volume in one second $\left(F E V_{1}\right)$ and forced mid expiratory flow rate $\left(F E F_{25-75}\right)$. Among the farmers, those doing dairy farming and silage work were the only groups on their own to have significantly reduced lung function. The results of this survey suggest the need for further exploration of the mechanism of an effect of farming occupations on lung function.

There have been several reports of lung disease in farmers and farmworkers, ${ }^{1}$ ranging from farmer's lung, an allergic alveolitis caused by thermophilic actinomycetes in mouldy hay, ${ }^{2}$ to the symptoms of wheezing and signs of obstructive airways disease associated with cereal harvesting. ${ }^{3-5}$ In a study of mortality patterns of farmers and farmworkers in the countries of the European Economic Community, an excess of deaths from respiratory disease was found among those employed in agriculture. ${ }^{6}$ In England and Wales the standardised mortality ratio (SMR) for agricultural employers was 132 for acute respiratory diseases (influenza, pneumonia, and acute respiratory infection) compared with 96 for men in the "equivalent" social class II; while for agricultural employees the SMR for this group of conditions was 246 compared with 206 in those of social class IV (their "equivalents"). ${ }^{6}$ For chronic bronchitis, emphysema, and asthma there was also an excess in employees. Since the death rate from lung cancer was found to be lower in agricultural employers and employees than in their social class equivalents, this excess seemed unlikely to be due to cigarette smoking, which sug-

Address for reprint requests: Dr RF Heller, Faculty of Medicine, University of Newcastle, Newcastle, New South Wales 2308, Australia.

Accepted 16 September 1985 gested the possibility of an occupation related risk for respiratory disease mortality. Being reflected in mortality statistics suggests that the problem may be more extensive than just the clinically recognised but numerically small respiratory diseases usually associated with farming. To explore this further, we set up a study to measure lung function and respiratory symptoms in a sample of farmers and farmworkers and controls in different parts of England and Wales.

\section{Methods}

Farms were identified by the Agricultural Inspectorate in each of six administrative regions of the Health and Safety Executive in England and Wales. Regional agricultural inspectors, who were informed that we were carrying out a lung function survey, were asked to draw at random, from one part of their region, 50 farms which were large enough to have at least two men working there and in which the farming was typical of the region as a whole (access to a full list of farms was not available to the investigators for reasons of confidentiality). Regional inspectors were particularly asked not to select farms on the basis of the presence or absence of any known lung disease as this could have biased the results of the survey. Each farm was contacted by letter and then by a telephone call to arrange a visit. The Regional Factory Inspectorate of the Health and 
Safety Executive, which was also informed of the purposes of the survey, was asked to supply names and addresses of non-agricultural employers situated in the same area as most of the farms in each region. A list of four to six companies employing 30 or more men in each region was provided (no special selection requirements were made, except that they were not to be in an industry known to be associated with an occupational lung disease); companies were contacted first by a letter informing them that we were carrying out a survey of chest illnesses in farmers and nonfarming controls and then by telephone, until an appropriate number had agreed to participate to provide enough controls in each region. All participants, both farmers and controls, were men aged 30-65 years and all were informed by letter of the reason for the study and told that they would be asked to fill in a questionnaire and blow into a lung function analyser.

A questionnaire was developed with the assistance of the Ministry of Agriculture, Fisheries, and Food and the Agricultural Division of the Health and Safety Executive. This questionnaire asked about type of farming occupation and included the standard Medical Research Council (MRC) questions about symptoms and about current and past smoking habits. The questionnaire was tried out in a pilot study in one part of South West England. Industrial controls had the same questionnaire apart from exclusion of the questions on farming occupation. Social class was assigned from the occupation according to the standard criteria of the Office of Population Censuses and Surveys. Subjects were asked to complete the questionnaire (self administered) at the time of the survey.

Respiratory function was measured on the farms and in the factories at suitable (and varied) sites, depending on a source of electricity and employees, and by the same observer (DMH). A Vitalograph spirometer (Vitalograph Ltd, Maids Moreton House, Buckingham; R Model No 20.640) was used with a function analyser (Vitalograph Ltd) for printing out the data. The spirometer was calibrated before the study started and at intervals throughout using a one litre syringe fitted with a two way valve. Since both farms and factories were studied in each region before we moved on to the next region, any drift in calibration over time would not affect the comparisons between cases and controls. Each subject had three test blows. The function analyser was cleared between each blow so that the forced vital capacity (FVC) used in determining the various indices of lung function was that measured in the same blow. Temperature was recorded each time with an alcohol thermometer attached to the side of the spirometer. Forced vital capacity, forced expiratory volume in one second $\left(\mathrm{FEV}_{1}\right)$, forced expiratory ratio (that is,
$\mathrm{FEV}_{1} / \mathrm{FVC} \times 100: \mathrm{FEV} \%$ ), and flow rates at lower $\stackrel{\vec{\Rightarrow}}{\vec{F}}$ lung volumes (forced mid expiratory flow rate $\stackrel{5}{?}$ $\left(\mathrm{FEF}_{25-75}\right)$ and forced end expiratory flow rate $\left(\mathrm{FEF}_{75-85}\right)$ ) were read from the function analyser $\frac{\bar{N}}{\overline{0}}$ printout. All measurements were converted to body $\frac{\pi}{\vec{D}}$ conditions (BTPS) by use of tables derived from a $\propto$ standard formula - temperature being entered but a constant atmospheric pressure ${ }^{7}$ in the range 740-760 $\vec{\circ}$ $\mathrm{mm} \mathrm{Hg}$ being assumed. For all lung function analyses the values recorded on the third blow were used. $\vec{\omega}$ Although for purposes of accurate characterisation of $\mathrm{FEV}_{1}{ }^{8}$ it may be preferable to exclude the lowest $\vec{x}$ results rather than take the third blow, by using this $A$ standardised method we at least avoid bias between i the cases and controls in this study. Analysis of the results on the basis of either the second or the third $\vec{V}$ blow or the mean of the two gives similar results.

Farmers and controls were surveyed at the same time of the year and usually between 0900 and 1700 ( $\mathrm{D}$ hours, although a small proportion of farmers (31 을 men) were tested between 0730 and 0900 .

Height (shoes removed) and weight (outer working jackets removed) were also measured. Data analysis $\vec{\oplus}$ was undertaken by use of SPSS (Statistical Package $\%$ for the Social Sciences) and GLIM (Generalised Linear Interactive Modelling). In the GLIM analysis each dependent variable (lung function test results as continuous variables and respiratory symptoms as binary variables in a logistic regression) could be $\mathbb{Q}$ compared between farmers and controls, any other $\overrightarrow{\vec{P}}$ potential confounding variable being taken into $\frac{0}{3}$ account, including height, weight, age, smoking hab- $\vec{J}$ its, social class, and geographical area. To explore the relationship of $\mathrm{FEV}_{1}, \mathrm{FEF}_{25-75}$, and $\mathrm{FEF}_{75-85}$ to the different variables independently of FVC, FVC was entered as an independent variable in the multiple $\underset{x}{\stackrel{0}{0}}$ regression analyses where $\mathrm{FEV}_{1}, \mathrm{FEF}_{25-75}$ and $\mathrm{FEF}_{75-85}$ were the dependent variables (for $\mathrm{FEV}_{1}$. this is a better adjustment than the calculation of $\delta$ FEV\% as it makes fewer assumptions about the relation of the two variables). To examine any effect 0 of area of country, the study was divided into three areas: the West (including the South West and Wales), the East (Norfolk and the East Midlands), and the centre (all other regions - see table 1). Social $\sigma$ classes were combined into three groups for analysis: N A-classes I and II and class III non-manual $\underset{\mathrm{C}}{\mathrm{N}}$ (includes farm owners and managers as well as indus- $\sigma$ trial managers); B-class III manual (skilled manual workers, including farm foremen); and C-classes IV $\stackrel{0}{=}$ and V (semiskilled and unskilled workers; most farm $\stackrel{\mathscr{\mathcal { S }}}{+}$ employees are in this group).

The tables present the results of the multiple $\frac{0}{0}$ regression analysis by giving the regression $\vec{\Phi}$ coefficients and their standard errors. From the size of $\overrightarrow{\mathbb{D}}$ the coefficient it is possible to see the size of the effect 
Table 1 Number of participants in each administrative region of the Health and Safety Executive

\begin{tabular}{|c|c|c|c|c|}
\hline Area & Region & Counties & Farmers* & Controls \\
\hline West & $\begin{array}{l}\text { South West } \\
\text { Wales }\end{array}$ & $\begin{array}{l}\text { Somerset } \\
\text { Dyfed }\end{array}$ & $\begin{array}{l}76 \\
30\end{array}$ & $\begin{array}{l}71 \\
56\end{array}$ \\
\hline East & Eastern & Norfolk & 97 & 43 \\
\hline & South East & Sussex, Kent, Hampshire, Berkshire & 148 & 140 \\
\hline Central & West Midlands & Herefordshire, Worcestershire & 34 & - \\
\hline Total & East Midlands & Lincolnshire & 43 & 46 \\
\hline
\end{tabular}

"In each table "farmers" includes farmers and farmworkers.

on the dependent variable being studied.

\section{Results}

Of 203 farms contacted, $146(72 \%)$ agreed to participate and $95 \%$ of the farmers and farmworkers in the relevant age group on these farms (428 subjects) actually took part. Of the 22 factories contacted, 12 industries agreed to let the employees participate as controls and 356 of the 468 eligible men (76\%) took part. Reasons for the non-participation of factories included having mainly female employees, reorganisation of the company, heavy work load, and not being able or willing to supply a random sample of workers. Table 1 shows the distribution of participating farmers and controls in each region. No controls were obtained from the West Midlands owing to a cancellation at the last minute but in the main extremes of farming types (that is, the east and west of the country) both farms and local industries were included. Table 2 compares the characteristics of farmers and controls.

From the job descriptions provided on the questionnaires, $50 \%$ of those working on farms gave their main occupation as general farmworkers, $19 \%$ as tractor drivers, and $12 \%$ as cowmen or stockmen. The remainder included managers, pigmen, poultrymen, etc. According to the replies to the questions on the tasks that were actually performed, $65 \%$ of

Table 2 Characteristics of farmers and controls

\begin{tabular}{lcc}
\hline & Farmers & Controls \\
\hline Number & 428 & 356 \\
Mean age (y) & 46.9 & 44.5 \\
Mean height $(\mathrm{cm})$ & 174.5 & 172.9 \\
Mean weight $(\mathrm{kg})$ & 78.3 & 76.8 \\
& $N o(\%)$ & No $(\%)$ \\
Ex-smoker & $132(32)$ & $129(36)$ \\
Smoked & $94(22)$ & $97(27)$ \\
$1-19 /$ day & $55(13)$ & $58(16)$ \\
$\geqslant 20$ day & $138(32)$ & $65(18)$ \\
Social group & $67(16)$ & $185(52)$ \\
A & $223(52)$ & $106(30)$ \\
B & & \\
C & & \\
\hline
\end{tabular}

those working on farms regularly performed cereal harvesting, $48 \%$ haymaking, and $42 \%$ silage making; $35 \%$ worked with beef cattle and calves; $29 \%$ sprayed crops regularly; while $22 \%$ did dairy farm work and $20 \%$ did cereal mixing or milling.

Table 3 shows the relationship between "chronic bronchitis" (defined here on the basis of the MRC questionnaire as cough or phlegm production or both for three months or more a year) and occupation, the multiple regression model taking into account cigarette smoking (which has a highly significant association with chronic bronchitis) and other variables; farmers were less likely to report the symptoms of chronic bronchitis than controls, but the difference was not statistically significant.

Table 4 shows the relationship of the entered variables to lung function measurement. Age had an independent significant relationship with all five measures of lung function. Height had a positive association with both $\mathrm{FVC}$ and $\mathrm{FEV}$, but a negative association with FEV\%. (To give an idea of the size of the effect of height, we see from the regression coefficients in table 4 that each centimetre increase in height is associated with an increase of 0.071 in FVC and 0.041 in FEV $_{1}$.) Heavy smokers (20 or more a day) had significantly lower $\mathrm{FEV}_{1}, \mathrm{FEV} \%, \mathrm{FEF}_{25-75}$, and $\mathrm{FEF}_{75-85}$. Those in social group $\mathrm{C}$ had significantly lower values for measures of lung function apart from $\mathrm{FEF}_{75-85}$ independently of the other factors (including smoking). Those living in central England had

Table 3 Multiple linear regression coefficients (and their standard errors) with reported symptoms of chronic bronchitis (MRC questionnaire) as dependent variable

\begin{tabular}{lr}
\hline Independent variable & \\
\hline Age & $0.01(0.01)$ \\
Farmer (cf control) & $-0.25(0.25)$ \\
Ex-smoker (cf non-smoker) & $0.37(0.37)$ \\
Smokes 1-19/day (cf non-smoker) & $1.13(0.36)^{*}$ \\
Smokes $\geqslant 20 /$ day (cf non-smoker) & $1.75(0.37) \dagger$ \\
Social class group B (cf group A) & $-0.30(0.32)$ \\
Social class group C (cf group A) & $-0.34(0.28)$ \\
Central England (cf west) & $0.17(0.27)$ \\
East England (cf west) & $0.04(0.30)$ \\
\hline * p $<0.01 ; \dagger p<0.001$. &
\end{tabular}


Table 4 Multiple linear regression coefficients (and their standard errors) with lung function measurements as dependent variables in turn

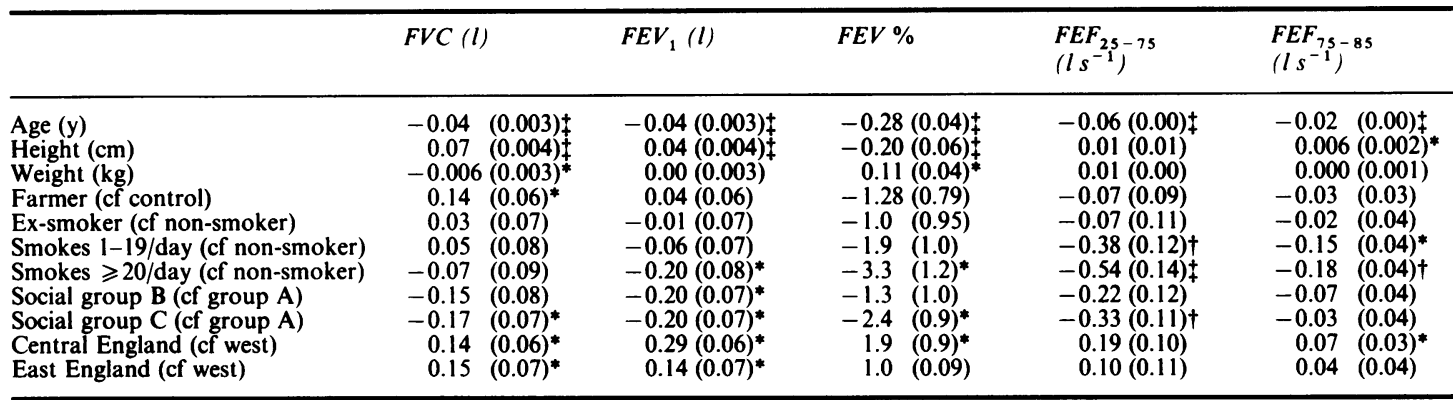

${ }^{*} \mathrm{p}<0.05 ; \mathrm{tp}<0.01 ; \mathrm{tp}<0.001$.

FVC - forced vital capacity; FEV $_{-}$-forced expiratory volume in one second; FEV\%—forced expiratory ratio; FEF $_{25-75}-$ forced mid $\neg$ expiratory flow; $\mathrm{FEF}_{75-85}$-forced end expiratory flow.

Table 5 Multiple linear regression coefficients with lung function measurements as dependent variables in turn; forced vital capacity entered as independent variable

\begin{tabular}{|c|c|c|c|}
\hline & $F E V_{1}(l)$ & $F E F_{25-75}\left(l s^{-1}\right)$ & $F E F_{75-85}\left(l s^{-1}\right)$ \\
\hline $\begin{array}{l}\text { Age (y) } \\
\text { Height (cm) } \\
\text { Weight (kg) } \\
\text { Farmer (cf control) } \\
\text { Ex-smoker (cf non-smoker) } \\
\text { Smokes } 1-19 / \text { day (cf non-smoker) } \\
\text { Smokes } \geqslant 20 / \text { day (cf non-smoker) } \\
\text { Social group B (cf group A) } \\
\text { Social group C (cf group A) } \\
\text { Central England (cf west) } \\
\text { East England (cf west) } \\
\text { FVC }\end{array}$ & $\begin{array}{l}-0.01(0.002) \ddagger \\
-0.01(0.003) \ddagger \\
0.01(0.002) \ddagger \\
-0.07(0.03)^{*} \\
-0.03(0.04) \\
-0.10(0.04)^{*} \\
-0.14(0.05)^{*} \\
-0.06(0.04) \\
-0.10(0.04)^{*} \\
0.07(0.04) \\
0.03(0.04) \\
0.75(0.02) \ddagger\end{array}$ & $\begin{array}{l}-0.03(0.005) \ddagger \\
-0.03(0.007)_{\ddagger}^{\ddagger} \\
0.01(0.004) \dagger \\
-0.16(0.08)^{*} \\
-0.08(0.10) \\
-0.38(0.11)^{\ddagger} \\
-0.49(0.12)^{\ddagger} \\
-0.15(0.11)^{\ddagger} \\
-0.23(0.10)^{*} \\
0.12(0.09) \\
0.02(0.10) \\
0.67(0.05) \ddagger\end{array}$ & $\begin{array}{cc}-0.02 & (0.002) \ddagger \\
-0.005 & (0.002)^{\ddagger} \\
0.002 & (0.001) \\
-0.053(0.028) \\
-0.02(0.03) \\
-0.15(0.04)^{*} \\
-0.17(0.04)^{*} \\
-0.05(0.04) \\
-0.01(0.03) \\
0.05(0.03) \\
0.01(0.03) \\
0.19(0.02) \ddagger\end{array}$ \\
\hline
\end{tabular}

*p $<0.05 ;$ tp $<0.01 ; \neq p<0.001$.

Abbreviations as in table 4 .

significantly higher FVC, FEV $_{1}$, FEV\%, and FEF $_{75-85}$ than those living in the west, whereas those living in eastern England had significantly higher FVC and $\mathrm{FEV}_{1}$ only when they were compared with those in the west. It has been suggested that correcting lung volumes to BTPS may give falsely high values at low ambient temperatures; ${ }^{9}$ we thus repeated the analyses without making the correction and this did not affect the findings reported. Farmers had a significantly higher FVC and a lower FEV\% and $\mathrm{FEF}_{25-75}$ (although for the last two the differences were not significant) than controls. When the FVC was entered into the model with $\mathrm{FEV}_{1}, \mathrm{FEF}_{25-75}$, and $\mathrm{FEF}_{75-85}$ as dependent variables in turn (to allow any effect of a higher FVC to be taken into account), farmers had significantly lower $F V_{1}$ and $\mathrm{FEF}_{25-75}$ and values for $\mathrm{FEV}_{75-85}$ just failed to show a significant difference at the $5 \%$ level (table 5 ).

When we looked at groups of farmers carrying out different tasks, those working regularly with dairy cattle and with silage were the only groups with a FEV\% significantly lower than that of controls and of the other farmers. The reduction was $3 \%$ for dairy farmers and $2.1 \%$ for silage workers. There was also a significant reduction in the $\mathrm{FEF}_{25-75}$ for the regu- $\frac{0}{0}$ lar dairy workers. For those working with beef 3 . cattle there was a similar pattern of decreases in lung $\delta$ function, which were not, however, statistically significant.

There was no observable interaction between geographical area and the farmer-control o comparison - that is, the differences in lung function between farmers and controls were not confined to 0 any one area of the country.

\section{Discussion}

This study has explored reported symptoms of respi-

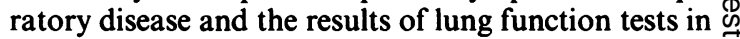
a sample of farmers representing farming conditions 7 across England and Wales and compared these with results from a random sample of control subjects $\mathbb{\mathbb { D }}$ from local industries. Although formal random sam- $\underset{\mathbb{Q}}{ }$ pling was not performed for the country as a whole, 
each region was asked to produce a representative sample of farms; for reasons of confidentiality the investigators were not allowed access to any lists, so the methods used in each region have been taken on trust. The main occupations given by those surveyed are very similar to those in two national surveys of farmers and farm workers, ${ }^{10}$ which supports the idea that we have identified a sample representative of those employed in farming in England and Wales.

There is no excess in farmers of symptoms associated with chronic bronchitis (that is, on the basis of the standardised MRC questions). The lung function measurements show many of the well known associations-such as the effect of age and cigarette smoking on measures of airways obstruction $\left(\mathrm{FEV}_{1}\right.$, $\mathrm{FEF}_{25-75}$, and $\mathrm{FEF}_{75-85}$ ). Also shown is the effect of social class on these measures-the effect of social class is independent of the effect of smoking habits, which thus are not enough to explain the social class gradient for airways obstruction. There are some geographical differences in lung function: those in the central and eastern areas have better FVC and FEV than those living in the west. These differences are not due to differences in temperature.

Farmers have significantly better FVC than controls ( 0.141 on average), even when the effect of greater height has been allowed for in the multiple regression analysis. This may be related to the exercise which is associated with farming occupations. Although the $\mathrm{FEV}_{1}$ levels alone did not differ significantly between farmers and controls, when $\mathrm{FEV}_{1}$ was expressed as a function of FVC (either as the traditional FEV\% or with FVC entered into the multiple regression formula) farmers had lower levels than controls. This difference thus suggests a degree of airways obstruction in farmers which may not be just a manifestation of a higher FVC. This pattern is seen across the range of farming activity, but appears among dairy farmers and silage workers in particular. Dairy farmers have previously been found to have worse lung function than controls. ${ }^{5}$ Cereal farmers are not singled out as being at special risk of altered lung function, despite abnormalities reported in North American grain handlers. ${ }^{3}$ This survey of a representative sample of farmers across England and Wales should be considered alongside the observations from mortality data ${ }^{6}$ that occupational factors encountered in farming may produce a particular risk for respiratory disease. Further exploration of the mechanism by which farming may be related to airways obstruction is warranted.

We are grateful to the Chest, Heart, and Stroke Association for financial support; to $\mathrm{Mr} \mathrm{J}$ Summerscales of the Agricultural Division and Mr K Wholmsley of the Factories Inspectorate of the Health and Safety Executive; to the late Mr S Houghton of the Ministry of Agriculture, Fisheries, and Food; and to Mr CV Brutey of the National Farmers Union for their help. We are also grateful to Miss Y Sittampalam and Miss S Chinn for statistical advice, and to the Office of Population Censuses and Surveys for the loan of the stadiometer to measure height.

Copies of the questionnaires used in this study have been lodged with the editor and further copies are available from the authors.

\section{References}

1 Seaton A. The breathless farm worker. $\mathrm{Br}$ Med $\mathrm{J}$ 1984;228: $1940-1$

2 Shelley E, Dean G, Collins D, Dinah F, Evans J, McHardy J. Farmer's lung: a study in North West Ireland. J Irish Med Ass 1979;72:261-4.

3 Dopico GA, Reddan W, Flaherty D, et al. Respiratory abnormalities among grain handlers. A clinical, physiologic, and immunologic study. Am Rev Respir Dis 1977;115:915-27.

4 Dosman JA. Chronic obstructive pulmonary disease and smoking in grain workers. Ann Intern Med 1977;87:784-6.

5 Babbott FD, Gump DW, Sylvester DL, MacPherson BV, Holly C. Respiratory symptoms and lung function in a sample of Vermont dairymen and industrial workers. Am J Public Health 1980;70:241-5.

6 Heller RF, Kelson MC. Respiratory disease mortality in agricultural workers in eight European countries of the European Community. Int J Epidemiol 1982;11: 170-4.

7 Cotes JE. Lung function: principles and application in medicine. 4th ed. Oxford: Blackwell, 1979.

8 Oldman PD, Cole TJ. Estimation of the FEV . Thorax 1983;38:662-7.

9 Cramer D, Peacock A, Denison D. Temperature corrections in routine spirometry. Thorax 1984;39:771-4.

10 Economic Development Committee for Agriculture. Agricultural manpower in England and Wales. London: HMSO, 1972:7. 